\title{
La «antonimia léxica» y la «antonimia gramatical» en los doce libros de Epigramas de Marcial
}

\author{
Pedro Juan Galán Sánchez \\ Universidad de Extremadura \\ pjgalan@unex.es
}

The «lexical antonymy» and the «grammatical antonymy»
in the twelve books of Martial's Epigrams

Este artículo analiza el uso que hace el poeta latino Marcial del procedimiento lingüístico-estilístico de la antonimia en la agudeza final de sus doce libros de Epigramas, como recurso de «humor intelectual». Marcial recurre a la antonimia, ya sea de naturaleza léxica (dare/accipere), ya sea de naturaleza gramatical (voz activa frente a voz pasiva: dare/dari; afirmación frente a negación: dare/non dare), en algo más de un tercio de sus epigramas $(36 \%)$. En el estudio se analizan tres diferentes estructuras de los epigramas de Marcial en relación con el uso de los antónimos.

Palabras clave: Marcial; epigramas; antónimos léxicos; antónimos gramaticales.
This paper analyses how the Latin poet Martial makes use of the linguistic-stylistic procedure of antonymy in the witty endings of his twelve books of Epigrams, as a resource of «intellectual humour». In slightly more than one-third of his epigrams (36\%) Martial resorts to this antonymy, whether it has a lexical nature (dare/accipere), or a grammatical one (active voice opposite to passive voice: dare/dari; affirmation opposite to denial: dare/non dare). This study analyses three different structures from Martial's epigrams in relation to the use of the antonyms.

Key words: Martial; epigrams; lexical antonyms; grammatical antonyms.

Uno de los recursos estilísticos más frecuentemente empleados por Marcial en la punta epigramática de sus composiciones es la figura retórica de la $a^{a} t^{\prime} e^{-} i^{1}{ }^{1}$. En la práctica, dicha figura se concreta en el empleo de dos procedimientos básicos: la «antonimia léxica» y la «antonimia gramatical». En un trabajo anterior nos ocupábamos del estudio de la antonimia léxica en la

${ }^{1}$ Sobre el uso de la figura de la antítesis en Marcial v. Kruuse 1941, pp. 286-288; y, más en particular, Cañizares Ferriz 1999. 
punta epigramática del libro I de los Epigramas ${ }^{2}$. En el presente estudio nos proponemos extender el análisis de la antonimia léxica al conjunto de los doce libros de Epigramas, al tiempo que ampliaremos la investigación al uso de la antonimia gramatical en ese mismo corpus ${ }^{3}$, prestando especial atención a las diferentes estructuras de los epigramas de Marcial en relación con el uso de la antonimia.

\section{La antonimia léxica}

En el libro I de los Epigramas la antonimia léxica afectaba aproximadamente a la cuarta parte de las composiciones (24,5\%). Pues bien, Marcial mantuvo esa misma proporción en el total de sus doce libros, en donde la antonimia aparece en 298 epigramas, de un total de $1175^{4}$ (25,3\%). Ello confirma, de manera definitiva, la enorme importancia que alcanza el uso de la antonimia léxica - como procedimiento de estilo y como recurso humorístico- en el conjunto de la obra epigramática del poeta latino. A este respecto, hay que subrayar que el recurso de la antonimia en Marcial se halla casi siempre al servicio de lo que Kruuse denominó en su día «humor intelectual» ${ }^{5}$. Así, frente al «humor sensorial»o «poético» (propio de la descripción de tipos y caracteres presente en la primera parte del epigrama), en donde el lector se limita a recibir las impresiones sensoriales que el poeta pone ante sus ojos mediante imágenes risibles, metáforas y comparaciones jocosas o hipérboles increíbles, en el humor intelectual (propio de la segunda parte del epigrama, es decir, de la agudeza final) el pensamiento del lector es conducido por el autor por determinadas vías hasta llegar, súbitamente, a una conclusión distinta de la que esperaba. De ello deriva una decepción, pero una decepción divertida, que es la que termina provocando la satisfacción cómica del lector. De acuerdo con ello, en la inmensa mayoría de los casos, Marcial reservará el empleo de la antonimia para la punta epigramática de sus composiciones,

2 V. Galán Sánchez 2000.

3 Dejamos fuera del estudio tanto el Liber de spectaculis como Xenia y Apophoreta, por tratarse de obras que se sitúan al margen de la unidad representada por los doce libros de Epigrammata. Sobre las múltiples diferencias (de metro, extensión, tema, tono, función y estructura) de Xenia y Apophoreta (libros XIII y XIV, respectivamente) con respecto a los otros doce libros v. Muñoz Jiménez 1996.

${ }^{4}$ Incluimos en la nómina Epigr. I pr.; IX pr., 95b.

${ }^{5}$ V. Kruuse 1941, pp. 265-271. 
lugar en el que aparecerán también otras figuras típicas del humor intelectual, como la anfibología, la polisemia, la paradoja, los juegos de palabras antitéticos, etc., recursos todos ellos muy apropiados para dar forma al aguijón final o fulmen in clausula característico de la mayoría de las composiciones de Marcial ${ }^{6}$.

Desde el punto de vista estructural, en el epigramista latino se pueden diferenciar tres tipos de composiciones en relación con el uso de la antonimia léxica ${ }^{7}$. Así, de forma minoritaria, en veintitrés ocasiones $(7,7 \%$ del total de los 298 epigramas), la antonimia se presenta como el recurso clave y fundamental del poema, en el sentido de que en unos cuantos versos (no más de seis) se acumulan dos, tres y hasta cuatro parejas de antónimos que recorren el epigrama de principio a fin ${ }^{8}$. Veamos un ejemplo de este primer procedimiento estructural al que podríamos denominar de «antonimia total» (Epigr. IV 83) ${ }^{9}$ :

Securo nihil est te, Naeuole, peius: eodem sollicito nihil est, Naeuole, te melius.

Securus nullum resalutas, despicis omnes, nec quisquam liber nec tibi natus homo est.

Sollicitus donas, dominum regemque salutas, inuitas. Esto, Naeuole, sollicitus.

Névolo, no hay nada peor que tú cuando estás tranquilo; cuando estás intranquilo, Névolo, no hay nada mejor que tú. Tranquilo, no le devuelves el saludo a nadie, menosprecias a todos y no ha nacido para ti ningún hombre libre ni persona alguna; intranquilo, no dejas de hacer regalos, saludas a tu 'amo' y 'señor' e invitas a todo el mundo: Névolo, estate intranquilo.

${ }^{6}$ Sobre el humor, en general, en Marcial, v. Barwick 1959, pp. 42-48; Szelest 1981; Malnati 1984; Sullivan 1989 y 1991, pp. 237-249; Holzberg 2002.

${ }^{7}$ Debemos advertir que este trabajo no pretende abordar el problema de la «estructura de los epigramas» de Marcial (unitaria, bipartita, tripartita, etc.), cuestión que ha sido objeto de abundante bibliografía (Lessing 1839, Kruuse 1941, Barwick 1959, Citroni 1969, Laurens 1989, Sullivan 1991, etc.). Lo que pretendemos es únicamente aclarar cómo se organiza en los epigramas, desde el punto de vista estructural, el recurso concreto de la antonimia.

${ }^{8}$ Epigr. I 22, 57, 81, 95, 115; II 9, 25; III 54, 79; IV 83; V 43, 83; VI 5; VII 13, 43; IX 50; X 69; XI 64, 68, 87; XII 12, 46, 79.

9 Para los textos de Marcial seguimos la edición de Fernández Valverde 2004-2005. Las traducciones son nuestras, si bien nos han sido de gran ayuda las versiones de Estefanía 1991, Ramírez de Verger 2001 y Montero 2004-2005. 
En el breve espacio de solo seis versos el epigramista latino ha acumulado hasta cuatro parejas de antónimos: securo/sollicito (por dos veces), peius/ melius; nullum/omnes y resalutas/salutas. Además, la primera y la última palabra del epigrama recogen, justamente, la oposición antonímica vertebradora de toda la composición: securo/sollicitus. Y el poema, en su conjunto, se construye sobre una clara paradoja (o antítesis conceptual): 'tu tranquilidad es mala; tu intranquilidad, buena' ${ }^{10}$.

Por lo demás, en este tipo de epigramas el efecto de la antonimia es aún mayor cuando la composición se reduce a un monodístico, como ocurre en el siguiente epigrama (Epigr. XII 46), en donde en solo dos versos se acumulan hasta tres parejas de antónimos: difficilis/facilis, iucundus/acerbus y cum/ sine $e^{11}$.

Difficilis facilis, iucundus acerbus es idem: nec tecum possum uiuere, nec sine te.

Eres al mismo tiempo difícil y fácil, amable y desabrido: ni puedo vivir contigo ni $\sin$ ti.

Un segundo tipo de composiciones de Marcial — también minoritario- se caracteriza por el hecho de que los antónimos se encuentran estratégicamente ubicados justo al comienzo y al final del epigrama. Ello ocurre en algo más de una treintena de poemas $(11,4 \% \text { del total de los } 298 \text { epigramas })^{12}$. En ocasiones se trata de poemas muy extensos, como el siguiente (Epigr. II 41) ${ }^{13}$ :

'Ride, si sapis, o puella, ride'

Paelignus, puto, dixerat poeta.

$\ldots$

${ }^{10}$ Por lo demás, es característico de Marcial la utilización de las mismas parejas antonímicas a lo largo de toda su creación poética. Así, por ejemplo, la oposición securus/ sollicitus vuelve a aparecer, tal cual, en la punta epigramática de Epigr. V 31: securus puer est sollicitumque pecus.

${ }^{11}$ El poema es de evidente inspiración ovidiana. Cf. Ou., Am. III 11.39: sic ego nec sine te nec tecum vivere possum.

${ }_{12}$ Epigr. I 73, 103; II 16, 41; III 76; IV 2, 9, 16, 30, 80, 86; VI 20, 33, 45, 50; VII 90; VIII 7, 76, 79; IX 3, 6, 102; X 1, 102; XI 39, 44, 56, 57, 75, 81, 100; XII 22, 66, 83.

${ }^{13}$ Sobre la semejanza estructural y funcional de los epigrammata longiora y los epigrammata breviora de Marcial (frente a lo que comúnmente se piensa), v. Ciocci 1985. 
At tu iudicium secuta nostrum

plora, si sapis, o puella, plora.

«Ríe, si sabes, jovencita, ríe», había dicho — me parece- el poeta pelignio. ... Tú, más bien, siguiendo mi consejo, llora, si sabes, jovencita, llora.

En este epigrama - de veintitrés versos- el paralelismo entre el comienzo y el final de la composición es absoluto, con la salvedad de que la elegante epanadiplosis del primer verso, ride si sapis, o puella, ride se ve sustituida en el último por otra distinta en la que los imperativos ride ... ride son reemplazados por sus antónimos correspondientes: plora ... plora. Y, de ese modo, Marcial acumula en la punta epigramática, en relación con el comienzo del poema, hasta cuatro recursos estilísticos: paralelismo, epanadiplosis, antítesis y -en el terreno de la intertextualidad - deformación humorística de la cita ovidiana ${ }^{14}$.

En otras ocasiones, la «antonimia inicial y final» se encuadra en poemas breves, como ocurre, por ejemplo, en el siguiente epigrama de solo cinco versos, en donde los términos uetulas y turpes, ubicados al comienzo de la composición, encuentran sus correspondientes antónimos en el último verso de la misma: puella y formosa (Epigr. VIII 79):

Omnes aut uetulas habes amicas

aut turpes uetulisque foediores.

Has ducis comites trahisque tecum

per conuiuia, porticus, theatra.

Sic formosa, Fabulla, sic puella es.

Todas tus amigas o son viejas o son feas, o más horrorosas incluso que las feas. Tú haces que te acompañen y las arrastras contigo por convites, pórticos y teatros: de ese modo, Fabula, eres tú guapa, de ese modo, Fabula, eres tú joven.

De parecida, aunque no idéntica factura, es este otro epigrama (Epigr. III 76):

Arrigis ad uetulas, fastidis, Basse, puellas, nec formosa tibi sed moritura placet.

${ }^{14}$ Marcial parece aludir al verso de Ou., Ars III 281: Quis credat? discunt etiam ridere puellae. Cf. Montero 2004-2005, vol. I, p. 75, n. 67, y Janka 2006. 
Hic, rogo, non furor est, non haec est mentula demens?

Cum possis Hecaben, non potes Andromachen!

Basso, te ponen las viejas, te repugnan las jóvenes, y no te gustan las guapas, sino las moribundas. Y yo me pregunto: ¿no es esto una locura, no es esta una polla estúpida?: ¡Pudiendo con Hécuba, no puedes con Andrómaca!

Marcial se sirve aquí de una de las parejas antonímicas que aparecían en el epigrama anterior ('viejas/jóvenes'), pero en esta ocasión los antónimos no se ubican - como ocurría en el ejemplo precedente- en el primer verso y el último, sino que ahora, tras colocar los antónimos en el verso inicial (uetulas ... puellas), lo que Marcial hace en el último es repetir esa misma pareja antonímica mediante el empleo de la figura retórica de la antonomasia (Hecaben ... Andromachen), en donde el nombre propio Hécuba (madre de Héctor) remite a 'vieja' y el nombre propio Andrómaca (esposa de Héctor) equivale a 'joven'.

El mismo procedimiento, «antonimia inicial y final», se da también en el siguiente epigrama compuesto únicamente por tres versos (Epigr. IV 9):

Sotae filia clinici, Labulla, deserto sequeris Clytum marito

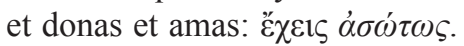

Marcial juega en esta ocasión con la paronomasia existente entre el nombre propio latino Sotas y el adverbio griego de la misma raíz $\alpha \sigma \omega ́ \tau \omega \varsigma^{15}$. Ahora bien, el juego de palabras no es de tipo meramente fónico, sino también semántico. En efecto, el prefijo privativo $\alpha$ - del adverbio griego denuncia que el autor ha buscado una «antonimia artificial» con el término Sotae, ubicado al comienzo de la composición: el vocablo Sotae alude claramente

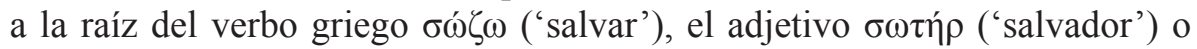
el sustantivo $\sigma \omega \tau \eta \rho i ́ \alpha$ ('salvación', 'curación'), raíz muy apropiada, dicho sea de paso, para el nombre de un médico. Y, de este modo, se establece una antonimia implícita entre el concepto de 'salvar' presente en Sotae y el

15 Otro ejemplo de antonimia entre vocablos latinos y griegos se encuentra en Epigr. VII 46: Diuitibus poteris musas elegosque sonantes / mittere: pauperibus munera $\pi \varepsilon \zeta \dot{\alpha}$ dato: «Podrás enviarles poemas y elegías melodiosas a los ricos: a los pobres danos regalos prosaicos». 
concepto de 'echar a perder' presente en ḋ $\sigma \omega ́ \tau \omega \varsigma$ ('perdidamente', 'disolutamente'). Si quisiéramos mantener el efecto antonímico, deberíamos buscar una traducción como la siguiente: «Labula, hija del médico Salvador, ... actúas perdidamente». Pero tal traducción arruinaría por completo el efecto cómico presente en la paronomasia Sotae/à $\sigma \omega ́ \tau \omega \varsigma$. Por ello, dando prioridad en este caso a la forma sobre el contenido, tal vez sería mejor una traducción de este tipo:

Labula, hija del médico Soluto, abandonando

a tu marido te vas con Clito y te entregas

y te enamoras de él: actúas disolutamente.

En todo caso, los dos procedimientos estructurales señalados - la «antonimia total» y la «antonimia inicial y final»— son minoritarios en Marcial, pues la suma de ambos representa únicamente el 19,1\% del total de los 298 epigramas que recurren al empleo de términos antonímicos. En la inmensa mayoría de los casos Marcial reservará el uso de la antonimia léxica únicamente para la agudeza final con la que suele cerrar sus epigramas. Y, de este modo, el tipo estructural fundamental en la obra del epigramista latino es el que podríamos denominar de «antonimia final». El autor recurre a este procedimiento en el $80,9 \%$ de los $\operatorname{casos}^{16}$. Los epigramas en cuestión pueden ser largos o breves, de carácter serio o humorístico, de tono grave o jocoso, de aliento festivo o burlesco, de contenido decoroso u erótico, de finalidad celebratoria o satírica, de estructura unitaria, bipartita o tripartita, de forma narrativa o dialogada. En definitiva, la antonimia se presenta en Marcial como un recurso universal, válido para todo tipo de epigramas, independientemente de su forma, estructura, extensión, finalidad, tono o contenido. Veamos un ejemplo de «antonimia final», ubicada en la punta epigramática de

${ }^{16}$ Epigr. I pr., 1, 3, 4, 8, 9, 10, 31, 35, 40, 51, 54, 59, 62, 63, 71, 72, 94, 97, 107, 108, 109, 110, 114; II 1, 3, 7, 8, 15, 18, 23, 24, 28, 30, 32, 36, 44, 49, 51, 52, 56, 58, 68, 82, 85, 90, 91; III $1,3,4,9,10,17,21,26,34,39,41,42,44,45,47,49,58,60,61,62,68,70,81,85,86$, $88,89,96$; IV 7, 15, 21, 34, 36, 37, 38, 55, 57, 61, 62, 71, 72, 75, 78, 79, 81; V 3, 18, 22, 31, $33,34,39,48,57,58,59,62,64,65,69,71,76,81,84$; VI 9, 10, 15, 16, 27, 29, 32, 34, 38, $41,66,71,79,80,82,84$; VII 16, 18, 25, 41, 46, 47, 54, 58, 71, 73, 81, 84, 85, 94, 95, 98; VIII $1,3,4,6,12,13,18,21,31,35,37,38,44,46,49,51,54,55,60,77,80$; IX pr., 5, 17, 25, 29 , $40,54,56,64,66,67,68,71,80,83,84,94,95 \mathrm{~b}, 99 ; \mathrm{X} \mathrm{2}, 8,11,14,17,26,46,47,75,79,80$, $81,82,83,92,103$; XI 3, 12, 17, 19, 22, 27, 28, 51, 61, 62, 63, 64, 67, 70, 71, 72, 78, 83, 89, 91, 96, 99, 104; XII 3, 15, 16, 18, 26, 28, 33, 34, 35, 37, 48, 53, 61, 68, 72, 80, 81, 94, 95. 
un poema largo (16 versos), de carácter serio y finalidad celebratoria, escrito en homenaje del emperador Domiciano (Epigr. V 65.15-16) ${ }^{17}$ :

Pro meritis caelum tantis, Auguste, dederunt

Alcidae cito di, sed tibi sero dabunt.

Augusto, por méritos tan excelsos los dioses al Alcida le concedieron pronto el cielo; a ti, en cambio, te lo concederán tarde.

Veamos ahora un ejemplo de «antonimia final» en un epigrama de solo dos versos, de carácter humorístico, tono jocoso y contenido erótico (Epigr. XII 26):

A latronibus esse te fututam

dicis, Saenia: sed negant latrones.

Afirmas, Senia, que te han follado unos bandidos: pero los bandidos lo niegan.

Una vez establecido el triple uso que hace Marcial de la antonimia léxica desde el punto de vista estructural («antonimia total», «antonimia inicial y final» $\mathrm{y}$ «antonimia final»), y una vez comprobado, asimismo, que la antonimia léxica es un recurso universal, aplicable a todo tipo de epigramas, nos detendremos a continuación en el tipo de antónimos concretos empleados por el epigramista latino. A este respecto, y dado que nuestro estudio es, más bien, de naturaleza estilística (no propiamente lingüístico), hemos tenido en cuenta no solo los antónimos propiamente dichos, sino cualquier tipo de expresión antitética. En este sentido, se pueden distinguir en Marcial tres tipos de oposiciones antonímicas:

a) «Antónimos propios», del tipo malas/bonas, facilis/difficilis, emis/ uendo, prope/longe, etc. Es el tipo de antonimia al que Marcial recurre la inmensa mayoría de las veces. Concretamente lo hace en el $84,3 \%$ de los casos (301 pares de antónimos de un total de 357). De todos modos, hay que advertir que en esta nómina incluimos algunas oposiciones cuya naturaleza antonímica no es del todo estricta, sino que se trata de «antónimos aproxi-

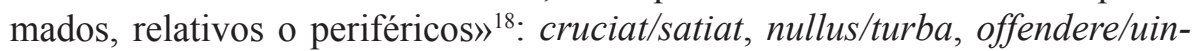

${ }^{17}$ El epigrama en cuestión constituye un elogio del emperador Domiciano, al cual se le compara con Hércules mediante el tópico del «sobrepujamiento»; cf. Galán Sánchez 1996.

${ }_{18}$ Cf. Varo 2007, p. 123: «Aunque convencionalmente la lengua fija los antónimos "perfectos" o "absolutos" (como bonito/feo), encontramos múltiples términos que pueden 
dicare, esurit/uorat, lassa/studiosa. O bien de «antónimos interactivos» ${ }^{19}$ : promittis/nega, petis/nego, rogabo/neges. O bien la antonimia se establece no a partir de los lexemas, sino a partir de la oposición de uno o varios «semas» concretos de los vocablos enfrentados ${ }^{20}$ : puer/uirum ('niño/adulto'), ueram/pictam ('verdadera/falsa'), aestatis/Decembri ('verano/invierno'), Gallum/uerna ('extranjero/indígena'), urbem/rus ('ciudad/campo'), rus/domus ('casa de campo/casa urbana'), gallus/uir ('afeminado/viril'), emptos/suos ('ajenos/propios'), orbos/patres ('sin hijos/con hijos'), unguentum/garum ('perfumado/maloliente'), hominum/dei ('mortales/inmortales'), cubili/lupanari ('casto/impúdico'), puerum/Giganta ('de pequeña envergadura/de gran envergadura'), pecudes/ferae ('domésticos/salvajes'), spectant/recitare ('ser espectador/actuar'), metuas/optes ('aborrecer/desear'), barbare/ciue ('extranjero/romano'), captiuam/uictrix ('vencida/vencedora'). O bien la antonimia surge a partir del uso de términos metafóricos o metonímicos: messes/hibernum: 'mieses' (= verano)/‘invierno'; auena/tubas: 'caramillo' (= poesía menor)/'trompetas' (= poesía mayor); uiuum/luteum: 'vivo' (= natural)/'de barro' (= 'artificial'). O bien la antonimia, en fin, se establece «por antonomasia». Veamos un ejemplo de este último tipo, situado en el aculeus de una composición de veintidós versos (Epigr. XI 104.21-22) ${ }^{21}$.

Si te delectat grauitas, Lucretia toto

sis licet usque die: Laida nocte uolo.

Si te agrada la seriedad, vale que seas una Lucrecia todo el día, pero por la noche quiero una Lais.

considerarse como antónimos "relativos" o "periféricos" (detestable, horrible, repugnantel bonito). Ello es especialmente frecuente en los "contextos literarios"”.

${ }^{19}$ Los pares antonímicos promittis/nega, petis/nego, rogabo/neges entran dentro del esquema que Cruse 1986, pp. 198-207, denomina «antónimos interactivos», es decir, aquellos en los que un término se opone conceptualmente a dos vocablos que, a su vez, son antónimos entre sí. Por ejemplo, 'pedir' se opone globalmente al par antonímico 'conceder/denegar', si bien el antónimo propiamente dicho de 'pedir' es únicamente 'conceder', de acuerdo con la doble oposición: 'pedir/conceder' y 'conceder/denegar'.

${ }^{20}$ Este tipo de «antonimia sémica» (no lexemática) a veces puede darse incluso entre vocablos sinónimos, como ocurre por ejemplo en español 'hospital/clínica', sinónimos desde el punto de vista lexemático, pero antónimos atendiendo a la oposición sémica 'público/ privado'. Cf. Varo 2007, p. 63, n. 22.

${ }^{21}$ A propósito de este epigrama v. Watson 2005. 
En esta ocasión, la punta epigramática contiene dos parejas antonímicas: una de ellas formada por antónimos propios ('día/noche') y otra por antónimos por antonomasia: 'Lucrecia' (= casta)/“Lais' (= impúdica) ${ }^{22}$.

b) «Antónimos impropios»: en este caso la oposición no se establece entre clases de palabras idénticas (como exigiría la antonimia propiamente dicha), sino diferentes: adverbio/adjetivo (indecenter/decentior), adverbio/ sustantivo ( $\dot{\alpha} \sigma \dot{\tau} \omega \varsigma /$ Sotae), adverbio/verbo (gratis/numerare), sustantivo/ adjetivo (egestas/diues), sustantivo/verbo (silentia/loqui) o adjetivo/verbo (nigra/albescere). Este tipo de oposición antonímica impropia constituye el $7,8 \%$ del total (28 casos) ${ }^{23}$. Veamos un ejemplo (Epigr. VI 84):

Octaphoro sanus portatur, Auite, Philippus.

Hunc tu si sanum credis, Auite, furis.

Avito, aunque Filipo está bueno, lo llevan en una litera de ocho porteadores. Si te piensas que él está bueno, Avito, es que tú estás loco.

En esta ocasión, la fuerza humorística del epigrama deriva de la conjunción de dos procedimientos semánticos: la polisemia y la antonimia. Por un lado, el adjetivo sanus ofrece, en el nivel paradigmático, dos acepciones, 'sano' y 'cuerdo', en función de que el contexto haga referencia a la salud física o la mental. Pues bien, en el nivel sintagmático, el primer verso de Marcial actualiza el primero de los dos significados: 'Filipo, aunque está bien de salud, es llevado en una litera de ocho porteadores'; en el segundo verso, en cambio, y gracias a la oposición antonímica del adjetivo sanus con el verbo furo, se actualiza la segunda de las acepciones: 'si te piensas que él está cuerdo, es que tú estás loco'. Y, de este modo, el término antonímico furis ('estás loco'), colocado estratégicamente al final del epigrama, modifica en el último momento el primer significado del adjetivo sanum ('sano'), haciéndole adquirir el segundo ('cuerdo'). En la traducción habría que intentar

${ }^{22}$ Los restantes «antónimos por antonomasia» presentes en la obra de Marcial son los siguientes: Gallo/Priapo ('castrado/con enorme pene'), Penelope/Helene ('fiel/infiel'), Veientana/Massica ('vino malo/vino bueno'), Hecaben/Andromachen ('vieja/joven'), Croeso/Iro ('rico/pobre'), Priami/Astyanacta ('viejo/nuevo'), Vergilius/Marsus ('buen poeta épico/mal poeta épico'), Gallus/Priapus ('castrado/con enorme pene').

${ }^{23}$ Epigr. II 1; III 3, 39, 85; IV 9, 72; V 48, 69; VI 5, 33, 84; VII 13; VIII 13, 51, 77; IX 3, 40, 50, 95b; XI 7, 19, 51, 62, 75, 87.1-3, 87.1-4; XII 22, 68. 
recoger el doble juego de Marcial: la anfibología (derivada de la polisemia) y la antonimia. Ello puede lograrse traduciendo sanus por 'bueno', ya que la expresión 'estar bueno' remite en español - lo mismo que el vocablo latino sanus - tanto al plano físico como al mental: 'estar bien de salud' o 'estar bien de la cabeza'24.

c) «Expresiones antonímicas»: en este caso uno o los dos términos de la oposición están conformados por un sintagma de dos o tres palabras: heredem reliquit/exheredauit; non facis gratis/accipis; lacrimas intus habet/ridet; post fata/uiuus, etcétera ${ }^{25}$. Marcial recurre al empleo de expresiones antonímicas en veintiocho ocasiones $(7,8 \% \text { del total })^{26}$. Veamos el siguiente ejemplo, en el que la antonimia 'delgada/gorda' queda plasmada mediante la oposición subtilem/mille librarum (dentro de un esquema de «antonimia inicial y final»), en el que el último verso termina, a su vez, con una antonimia gramatical del tipo «afirmación/negación» (sum/non sum) y con la oposición de los vocablos «cohipónimos» carnarius/pinguiarius (Epigr. XI 100):

Habere amicam nolo, Flacce, subtilem, cuius lacertos anuli mei cingant, quae clune nudo radat et genu pungat, cui serra lumbis, cuspis eminet culo. Sed idem amicam nolo mille librarum. Carnarius sum, pinguiarius non sum.

Flaco, no quiero tener una amante delgada, cuyos brazos puedan ser ceñidos por mis anillos, que me raspe con su rabadilla desnuda y me pinche con sus rodillas, a la que le sobresalga un serrucho en la espalda y una púa en el culo. Pero tampoco quiero yo una amante de trescientos kilos: me gusta la carne, no me gusta la grasa.

${ }^{24}$ Sobre la anfibología o «desdoble de las valencias semánticas de las palabras» en Marcial v. Echave-Sustaeta 1958, y Pizarro Sánchez 1999.

${ }^{25}$ En Epigr. IX 25 la expresión antonímica impropia 'mirar/ciego' se establece por antonomasia: Si non uis teneros spectet conuiua ministros, / Phineas inuites, Afer, et Oedipodas («Afro, si no quieres que los convidados miren a tus delicados criados, invita a tu mesa a Edipos y Fineos» = 'ciegos').

${ }^{26}$ Epigr. I 1, 3, 8, 95, 108, 114, 115; II 16, 24, 36; III 10, 17, 26, 44; IV 37; V 18; VI 5, 29; VII 25; VIII 38; IX 25, 102; X 80; XI 67, 83, 100; XII 12, 48. 


\section{La antonimia gramatical}

Habitualmente se habla de «antonimia gramatical» para referirse a los antónimos morfológicos, es decir, aquellos que establecen el significado antonímico por la presencia o ausencia de un prefijo de valor negativo sobre la base de un mismo lexema: utilis/inutilis. Pero lo cierto es que tal oposición, basada en un mecanismo meramente formal, no es en realidad demasiado relevante; además, no parece muy adecuado denominarla «antonimia gramatical», pues la oposición 'útil/inútil' sigue siendo tan lexical como, por ejemplo, la oposición 'beneficioso/perjudicial'. Para estos casos sería más oportuno hablar de «antonimia morfolexical» ${ }^{27}$. Por «antonimia gramatical» se ha de entender, más bien, la oposición semántica llevada a cabo no por procedimientos léxicos, sino por procedimientos gramaticales. Y así, los «antónimos gramaticales» serían aquellos que - al no encontrarse lexicalizados- basan su relación antonímica bien en la oposición gramatical de voz: «activa/pasiva» (dare/dari), bien en el mecanismo de la «afirmación/negación» (dare/ non dare).

El primer tipo de «antonimia gramatical» tiene su equivalencia, en el plano léxico, en los antónimos denominados «inversos» o «recíprocos» (dare/ accipere). En efecto, la oposición que se da en el plano gramatical entre darel dari es semejante a la existente, en el plano semántico, entre dare/accipere ${ }^{28}$. En ambos casos se trata de la expresión de una misma acción desde dos perspectivas inversamente polarizadas: 'dar/ser dado' = 'dar/recibir'. En los dos pares antonímicos se da una relación de «reciprocidad necesaria y simultánea», que es justamente lo que caracteriza a los denominados «antónimos inversos». De hecho, con relativa frecuencia conviven en una misma lengua los dos procedimientos - el léxico y el gramatical - para expresar la «antonimia inversa»:

Lat. dare/accipere (esp. 'dar/recibir'): antonimia léxica, lat. dare/dari (esp. 'dar/ser dado'): antonimia gramatical, lat. uincere/cedere (esp. 'ganar/perder'): antonimia léxica, lat. uincere/uinci (esp. 'vencer/ser vencido'): antonimia gramatical.

27 Sobre la antonimia morfolexical v. Guilbert 1964; Duchácek 1965, p. 56.

${ }^{28}$ Cf. García Hernández 1987, p. 247: «La complementariedad léxica corresponde en el nivel gramatical a la categoría de voz». 
Pues bien, este primer tipo de antonimia gramatical no es demasiado utilizado por Marcial, ya que solo aparece en la punta epigramática de 17 composiciones ( $1,4 \%$ del total de 1175 epigramas). Pero, de todos modos, tal procedimiento no deja de estar presente en casi todos los libros ${ }^{29}$. Por lo general, la fuerza estilística mayor de esta clase de antonimia tiene lugar cuando el sujeto gramatical de los dos antónimos es el mismo, como ocurre, por ejemplo, en el siguiente monodístico, en el que la oposición «activa/pasiva» se erige no solo en el único recurso de agudeza, sino en la propia razón de ser del poema (Epigr. III 97):

Ne legat hunc Chione, mando tibi, Rufe, libellum.

Carmine laesa meo est: laedere et illa potest.

Te pido, Rufo, que Quíone no lea este libro. Fue herida por mis versos: también ella puede herir.

O como ocurre en la agudeza final del siguiente epigrama, basada en una sentencia gnómica formulada mediante la oposición «activa/pasiva» (Epigr. VI 11.8-10):

uis te purpureum, Marce, sagatus amem?

Vt praestem Pyladen, aliquis mihi praestet Oresten.

Hoc non fit uerbis, Marce: ut ameris, ama.

¿quieres que yo, vestido con un sayo, te ame a ti, Marco, que vistes de púrpura? Para mostrarme yo como un Pílades, que alguien se me muestre a mí como un Orestes. Eso no se logra con palabras, Marco: para ser amado ama.

Y lo mismo ocurre también en el cierre de esta otra composición (Epigr. VII 28.9-10):

'Scire libet uerum? Res est haec ardua'. Sed tu quod tibi uis dici dicere, Fusce, potes.

«¿Te gusta saber la verdad? Eso es una cosa complicada». Pero tú puedes decirme, Fusco, lo que quieres que se te diga.

${ }^{29}$ Epigr. I 111; II 19, 55; III 5, 69, 97; IV 68; V 42, 66, 67; VI 11; VII 23, 28; VIII 45, 56; IX 72; XI 12. En dos casos la estructura es la de «antonimia inicial y final» (II 19 y VIII 45). En cuatro casos la antonimia «activa/pasiva» se establece mediante sinónimos: donatur/ dederis, discerpi/lacerauit, diligeris/amat, ferres/dari (V 42, 67, VIII 56; IX 72). 
El segundo tipo de «antonimia gramatical» (basado en el mecanismo de la «afirmación/negación»: 'hablar/no hablar') tiene su equivalencia, en el plano léxico, en la antonimia denominada «complementaria» (loqui/tacere) ${ }^{30}$, oposición gramatical que, en este caso concreto, se halla lexicalizada en muchas lenguas, como ocurre, por ejemplo, en español o en latín ('hablar/callar', loqui/tacere). De hecho, con frecuencia las lenguas, para designar una misma realidad conceptual, se sirven de los dos procedimientos, dependiendo de la clase de palabra en cuestión ${ }^{31}$ :

— Sustantivos: lat. uisus/caecitas (esp. 'vista/ceguera'): antonimia léxica.

- Adjetivos: lat. uidens/caecus (esp. 'vidente/ciego'): antonimia léxica.

— Verbos: lat. uidere/non uidere (esp. 'ver/no ver'): antonimia gramatical.

Pues bien, este segundo tipo de «antonimia gramatical» («afirmación/ negación») es ampliamente utilizado por Marcial en su obra epigramática, ya que aparece en la agudeza final de 145 composiciones $(12,3 \%$ del total de 1.175 epigramas ${ }^{32}$. En dicha nómina incluimos los antónimos gramaticales introducidos por las marcas de negación típicas de la lengua latina (non, nec y ne), pero también los introducidos, esporádicamente, por una serie de partículas negativas que presuponen implícitamente la negación de toda la frase (nemo, nullus, nihil, nunquam, nondum, nusquam o nil unquam), así como los introducidos por las perífrasis negativas «nolo + infinitivo» (carpis/noli carpere; nega/noli negare), «desino + infinitivo» (miraris/desine mirari) y «desum + infinitivo» (coepit fingere/desit fingere), ya que todas estas expresiones dan lugar, en última instancia, a una expresión antitética.

En el tipo estándar de esta clase de antonimia gramatical los dos términos de la oposición antonímica se hallan normalmente expresos (Epigr. I 13. 3-4):

'Si qua fides, uulnus quod feci non dolet', inquit, 'sed tu quod facies, hoc mihi, Paete, dolet'.

${ }^{30}$ Este tipo de antonimia ya fue visto en el siglo XVI por un gramático como el Brocense, (v. Sánchez Salor y Chaparro 1984, pp. 244-246), quien, desde el punto de vista retórico, clasifica los «argumentos contrarios» en cuatro tipos: adversos (virtud/vicio), relativos (señor/ siervo), privativos (sobrio/ebrio) y contradictorios (enseñar/no enseñar).

${ }^{31}$ Para los sustantivos y adjetivos es habitual la «antonimia léxica»; en cambio, para muchos verbos es bastante frecuente la «antonimia gramatical».

${ }^{32}$ Aparece también al final de la epístola introductoria del libro XII: ne Romam, si ita decreueris, non Hispaniensem librum mittamus, sed Hispanum [mittamus]. 
«Créeme — dijo—, no me duele la herida que yo me he hecho: me duele, Peto, la que tú vas a hacerte» ${ }^{33}$.

Pero con frecuencia uno de ellos se encuentra elidido (Epigr. XI 92) ${ }^{34}$ :

Mentitur qui te uitiosum, Zoile, dicit.

Non uitiosus homo es, Zoile, sed uitium.

Miente quien dice, Zoilo, que tú eres un vicioso; no eres un vicioso, Zoilo, sino el vicio mismo.

La inmensa mayoría de las veces la antonimia gramatical es pura (non luget/luget), pero en ocasiones Marcial lleva a cabo la oposición antonímica mediante vocablos sinónimos (non luget/dolet), como ocurre, por ejemplo, en la siguiente punta epigramática (Epigr. I 33. 3-4) 35 :

Non luget quisquis laudari, Gellia, quaerit:

ille dolet uere qui sine teste dolet.

No siente aflicción, Gelia, quien busca que lo alaben: sufre de verdad el que sufre sin testigos.

La utilización de sinónimos obedece casi siempre a razones métricas o estilísticas, pero a veces la causa es más profunda, como ocurre, por ejemplo, con la siguiente agudeza final (Epigr. II 17.4-5):

Sed ista tonstrix, Ammiane, non tondet, non tondet, inquam. Quid igitur facit? Radit.

Pero esa peluquera, Amiano, no te corta el pelo. No te corta el pelo, digo. ¿Qué hace entonces?: te deja pelado ${ }^{36}$.

${ }^{33}$ Como en tantas otras ocasiones, Marcial acumula en la punta epigramática no una, sino varias oposiciones. Y así, además de la antonimia gramatical non dolet/dolet, encontramos una doble oposición de persona (1. $\left.{ }^{\mathrm{a}} / 2{ }^{\mathrm{a}}\right)$ y de tiempo (pasado/futuro) en el par feci/facies. Sobre los epigramas dialogados v. Del Barrio Vega 1989.

${ }^{34}$ V. también, Epigr. I 34, 40, 63, 66; II 5, 46; III 21, 67, 84; IV 53; V 45, 61; VI 16, 48, 67; VII 55, 69, 77, 86; IX 14, 19, 56, 57, 62, 79, 95b; X 55; XI 10, 33; XII 10, 30, 89.

${ }^{35}$ V. también Epigr. II 17; III 6; VIII 56, 59; IX 24; X 74; XI 37, 52; XII 17, 27.

${ }_{36}$ No creemos que radit tenga aquí un sentido erótico. Para la discusión v. Ramírez de Verger 2001, vol. I, p. 99, n. 42, y Montero 2004-2005, vol. I. p. 69, n. 35. 
En esta ocasión la antonimia gramatical se realiza por medio de sinónimos (non tondet/radit), y no mediante antónimos puros (non tondet/tondet), debido a que el doble significado del verbo rado ('cortar el pelo o la barba'/ 'desplumar o dejar pelado') le permite a Marcial jugar con esa dilogía, en torno a la cual se condensa toda la gracia del epigrama.

En lo que se refiere a la construcción de la antonimia gramatical del tipo «afirmación/negación», encontramos, como era de esperar — por tratarse de recursos estilísticos equivalentes - las mismas tres estructuras que aparecían a propósito de la «antonimia léxica», a saber: «antonimia total», «antonimia inicial y final» y «antonimia final».

La «antonimia total» aparece únicamente en cinco ocasiones (3,4\% del total de los 145 epigramas) ${ }^{37}$, siempre en composiciones muy cortas (de dos a cuatro versos), en las que la «afirmación/negación» se presenta como el recurso clave y fundamental del poema, de modo tal que todo el epigrama se vertebra en torno a dichas expresiones antonímicas. Veamos como ejemplo el siguiente monodístico, en el que aparecen dos pares de antónimos gramaticales (Epigr. I 91):

Cum tua non edas, carpis mea carmina, Laeli.

Carpere uel noli nostra uel ede tua.

Aunque tú no publicas tus versos, criticas, Lelio, los míos: o no critiques los míos o publica los tuyos ${ }^{38}$.

Las expresiones antonímicas aparecen colocadas en estructura quiástica (non edas - carpis/carpere noli - ede), lo mismo que la oposición entre los posesivos de primera y segunda persona (tua - mea/nostra - tua). Por su parte, la modalidad enunciativa de los verbos del primer verso se opone a la modalidad imperativa de los del segundo (non edas/ede; carpis/carpere noli), al tiempo que los conceptos 'criticar' y 'publicar' se oponen entre sí en el último verso mediante una disyunción exclusiva ( $u e l$... uel). En definitiva, en el apretado espacio de solo dos versos Marcial acumula varios artificios estilísticos de naturaleza puramente lingüística.

\footnotetext{
37 Epigr. I 91; II 33; III 90; VIII 33; IX 8.

${ }^{38}$ En otras ocasiones es un único par de antónimos gramaticales el que recorre toda la composición: Epigr. II 33: non basio ... non basio ... non basio ... basiat; III 90: uult, non uult ... uult et non uult ... uelit; VIII 33: ... cum mittere possis, mittere cum possis ... cum mittere possis ... cum possis mittere, Paule, nihil.
} 
La misma estructura de «antonimia total» constituye el armazón sobre el que se construye el siguiente epigrama de cuatro versos (Epigr. IX 8):

Nil tibi legauit Fabius, Bithynice, cui tu annua, si memini, milia sena dabas.

Plus nulli dedit ille. Queri, Bithynice, noli: annua legauit milia sena tibi.

No te ha legado nada Fabio, ese al que tú le dabas, Bitínico — si no recuerdo mal-, seis mil sestercios al año. No te quejes, Bitínico, a nadie le ha dado Fabio más que a ti: te ha legado seis mil sestercios al año.

De nuevo, las expresiones antonímicas se encuentran colocadas en estructura quiástica (nil legauit - dabas/nulli dedit-legauit). Pero en esta ocasión la fuerza humorística del epigrama surge, sobre todo, a partir de la sorprendente paradoja (o «antonimia conceptual») según la cual 'no legar' = 'legar'. Y tal paradoja se articula no solo a partir de la doble «antonimia gramatical» (non legare/legare, non dare/dare), sino también a partir de la «sinonimia» existente entre los términos dare ('dar') = legare ('dar en herencia'). En efecto, como señala B. García Hernández, el contraste entre el archilexema o término neutro dare y el lexema marcado legare conduce a la paradójica conclusión de que 'no dar Bitínico' es igual a 'dar en herencia Fabio'39.

En lo que se refiere a la «antonimia inicial y final», tal estructura compositiva aparece constatada en 15 composiciones (10,3\% del total de los 145 epigramas $)^{40}$. En ocasiones se trata de poemas muy extensos como el siguiente, compuesto mediante un claro esquema de priamel (Epigr. IX $57)^{41}$ :

Nil est tritius Hedyli lacernis:

non ansae ueterum Corinthiorum, nec crus compede lubricum decenni, nec ruptae recutita colla mulae, nec quae Flaminiam secant salebrae, nec qui litoribus nitent lapilli,

${ }^{39}$ Cf. García Hernández 1987, p. 242.

${ }^{40}$ Epigr. I 64; III 51, 86; IV 39, 43; VI 22; VII 39, 43; VIII 76; IX 35, 57; X 74, 90; XI 23; XII 17.

${ }^{41}$ Sobre este epigrama v. La Penna 1992. 
nec Tusca ligo uinea politus, nec pallens toga mortui tribulis, nec pigri rota quassa mulionis, nec rasum cauea latus uisontis, nec dens iam senior ferocis apri.

Res una est tamen -ipse non negabit-

culus tritior Hedyli lacernis.

Nada está más desgastado que los mantos de Hédilo: ni las asas de los viejos vasos de Corinto, ni el pie desollado por unos grilletes de diez años, ni el pescuezo despellejado de una mula derrengada, ni las rodadas que surcan la vía Flaminia, ni las piedrecillas que brillan en las playas, ni el azadón pulido por el viñedo etrusco, ni la toga descolorida de un pobrete difunto, ni las ruedas gastadas de un carretero negligente, ni los costados de un bisonte raspados por la jaula, ni los colmillos ya añosos de un fiero jabalí. Pero sí, sí hay una cosa —él mismo no podrá negarlo_- el culo de Hédilo está más desgastado que sus mantos.

En esta ocasión la «antonimia inicial y final» adquiere toda su fuerza humorística debido al contraste violento que se produce entre dicha «antonimia» (nil est/est) y el «paralelismo» casi absoluto de los versos que abren y cierran la composición (nil est tritius Hedyli lacernis/culus tritior [est] Hedyli lacernis $)^{42}$; paralelismo roto abruptamente por medio del aprosdóketon representado por el vocablo —inesperado, grotesco y grosero-culus. Y en medio de todo ello, Marcial inserta, a modo de sabia y morosa preparación para el aculeus final, una de sus típicas cumulationes (cargada del característico realismo del autor), en la que a lo largo de diez versos consecutivos —introducidos todos ellos por la anáfora non... nec... nec... nec- enumera un abigarrado elenco de objetos muy heterogéneos, pero que comparten un rasgo en común: su profundo desgaste ${ }^{43} \ldots$, pero no tan profundo, en todo caso, como el «desgaste» sufrido por el culus de Hédilo. Por lo demás, de acuerdo con una técnica muy frecuente en Marcial, el significado último de la composición habrá de completarse fuera ya del poema, en la mente del lector,

${ }^{42}$ Un artificio similar se da en Epigr. IV 43, cuyo verso inicial: Non dixi, Coracine, te cinaedum encuentra su réplica en el verso final: Dixi te, Coracine, cunnilingum.

${ }^{43}$ Sobre el recurso de la cumulatio en Marcial, v. Salemme 1976 y 1987. Sobre la función de las cumulationes como hábil preparación para dotar de mayor fuerza al aculeus, v. Kruuse 1941, pp. 255-258. 
quien a partir del concepto expreso de culus tritus podrá llegar con facilidad a la acusación tácita de Marcial, objeto último del chiste del epigrama: la homosexualidad pasiva de Hédilo.

En otras ocasiones, la «antonimia inicial y final» aparece en epigramas breves, como el siguiente de cuatro versos (Epigr. I 64):

Bella es, nouimus, et puella, uerum est,

et diues, quis enim potest negare?

Sed cum te nimium, Fabulla, laudas,

nec diues neque bella nec puella es.

Eres guapa, Fabula, lo sabemos, y joven, es cierto, y rica, ¿quién puede negarlo? Pero, cuando te alabas tantísimo a ti misma, no eres ni rica ni guapa ni joven.

En todo caso, los dos procedimientos estructurales señalados para la antonimia gramatical del tipo «afirmación/negación» («antonimia total» y «antonimia inicial y final») son de nuevo minoritarios en la obra de Marcial, pues la suma de ambas estructuras únicamente supone al 13,7\% del total de 145 epigramas. El tipo estructural fundamental en la obra del epigramista latino vuelve a ser aquí el que hemos denominado «antonimia final», presente en 126 composiciones $(86,9 \%)^{44}$. A veces se trata de poemas extensos; otras, de poemas breves; otras, de composiciones de mediana extensión. Veamos, a modo de ejemplo, la agudeza final del siguiente epigrama de ocho versos, en cuyo último dístico se acumulan dos parejas de antónimos gramaticales del tipo «afirmación/negación»: uideam/non uideam; piget/non piget (Epigr. II 5):

Ne ualeam, si non totis, Deciane, diebus et tecum totis noctibus esse uelim, sed duo sunt quae nos disiungunt milia passum; quattuor haec fiunt, cum rediturus eam.

${ }^{44}$ Epigr. I 13, 18, 32, 33, 34, 40, 43, 46, 63, 66, 71, 90, 110, 112; II 3, 5, 7, 9, 12, 15, 17, 28, 30, 46, 56, 60, 63, 64, 76, 80; III 6, 9, 21, 34, 36, 37, 54, 64, 67, 70, 75, 76, 84, 99; IV $10,12,36,37,38,53,66,71,81$; V 9, 13, 15, 32, 41, 45, 61; VI 2, 7, 16, 26, 28, 48, 55, 67, 69, 70, 75, 89; VII 10, 36, 42, 55, 69, 75, 77, 86; VIII 20, 24, 55, 56, 59, 64; IX 10, 14, 19, 24, 49, 56, 62, 67, 70, 77, 79, 95b; X 11, 31, 40, 41, 55, 58; XI 10, 12, 33, 37, 52, 64, $67,79,86,92,100$; XII 10, 20, 23, 27, 30, 55, 71, 80, 88, 89, 91. 
Saepe domi non es, cum sis quoque, saepe negaris, uel tantum causis uel tibi saepe uacas.

Te tamen ut uideam, duo milia non piget ire; ut te non uideam, quattuor ire piget.

Que me muera, si no quiero yo estar contigo, Deciano, todos los días y todas las noches. Pero nos separan dos mil pasos, que pasan a ser cuatro mil cuando tengo que volver. Con frecuencia no estás en casa, y aunque estés, con frecuencia me dicen que no estás: sólo tienes tiempo para tus pleitos o para ti. En todo caso, para verte no me molesta andar dos mil pasos; para no verte, me molesta andar cuatro mil.

Por lo demás, dado que la «antonimia léxica» y la «antonimia gramatical» constituyen - como ya ha quedado dicho- las dos caras de un mismo procedimiento estilístico, no puede sorprender que hasta en 23 epigramas Marcial haga uso, simultáneamente, de ambos procedimientos lingüísticos en la agudeza final de sus composiciones ${ }^{45}$. Veamos un epigrama ilustrativo de este tipo mixto de «antonimia léxico-gramatical» (Epigr. II 56):

Gentibus in Libycis uxor tua, Galle, male audit immodicae foedo crimine auaritiae.

Sed mera narrantur mendacia: non solet illa accipere omnino. Quid solet ergo? Dare.

Entre los pueblos de Libia se meten con tu esposa, Galo, por el feo defecto de una codicia desmedida. Pero no cuentan más que puras mentiras. Ella no suele, en absoluto, recibir. ¿Qué es lo que suele hacer?: entregarse.

El dístico final se construye sobre una «antonimia gramatical» (non solet) solet) al tiempo que sobre una «antonimia léxica» (accipere/dare) ${ }^{46}$. Por lo demás, la gracia del epigrama surge de la anfibología presente en uno de los antónimos léxicos: dare significa 'dar' (antónimo de accipere, 'recibir'), pero, con sentido erótico, también significa 'darse o entregarse sexualmen-

${ }^{45}$ Epigr. I 110; II 3, 9, 56; III 9, 34, 54, 70, 76; IV 36, 37, 38, 71, 81; VI 16; VII 43; VIII 55, 76; IX 95b; X 11; XI 64, 67; XII 80. Por su parte, en VIII 56 se combinan la antonimia del tipo «activa/pasiva» (diligeris/amat) y la del tipo «afirmación/negación» (non diligeris/ amat).

${ }^{46}$ Sobre el campo semántico de la «donación» en Marcial y las relaciones clasemáticas del mismo, v. García Hernández 1987. 
te $^{97}$, que es el significado que finalmente acaba actualizándose en la mente del lector, quien en el último momento comprende que no es la avaritia (las ansias de recibir) el mayor defecto de la esposa de Gala, sino la luxuria (las ansias de entregarse sexualmente) ${ }^{48}$.

En una ocasión incluso Marcial combina en el epigrama los tres tipos de antonimia analizados en este trabajo (Epigr. XI 12):

Ius tibi natorum uel septem, Zoile, detur, dum matrem nemo det tibi, nemo patrem.

Que se te conceda, Zoilo, el «derecho de los tres hijos» (y hasta de siete), con tal de que nadie te conceda a ti ni un padre ni una madre.

Toda la composición se halla montada sobre el recurso lingüístico-estilístico de la antonimia: natorum/pater, mater («antonimia léxica»); detur/det (antonimia gramatical del tipo «activa/pasiva»); detur/nemo det (antonimia gramatical del tipo «afirmación/negación»).

\section{Conclusiones}

La antonimia léxica y la antonimia gramatical constituyen, en Marcial, las dos caras de un mismo procedimiento estilístico. Ambos mecanismos lingüísticos son profusamente explotados por el poeta latino - como elemento de «humor intelectual»- a lo largo de toda su producción poética. De hecho, seguramente estemos ante el recurso literario más frecuentemente empleado por el bilbilitano en la punta epigramática de sus composiciones. Así, en el total de los 1175 epigramas analizados, la antonimia léxica se halla presente en la agudeza final de 298 composiciones, mientras que la antonimia gramatical aparece 162 veces (17 casos de oposición «activa/pasiva» + 145 casos de «afirmación/negación»), lo que ofrece una suma total de 460 epigramas. A esa cifra hay que restarle 26 casos en los que confluyen varios tipos de antonimia y que, por ello mismo, han sido computados en nuestro estudio más 1991.

${ }^{47}$ Sobre el léxico erótico de Marcial v. Rodriquez 1981; Fortuny Previ 1986, y Montero

${ }^{48}$ La misma anfibología, pero llevada a cabo mediante antónimos gramaticales (uis dare nec dare uis) aparece en Epigr. VII 75: Vis futui gratis, cum sis deformis anusque. / Res perridicula est: uis dare nec dare uis. 
de una vez (es decir, tanto en el apartado de la antonimia léxica como en el de la gramatical). Ello ofrece un total de 434 composiciones que presentan en su punta epigramática algún tipo de antonimia. En muchas ocasiones, como es natural, no se trata del único recurso de agudeza presente en el acumen, sino que a menudo Marcial emplea la antonimia en combinación con otros artificios literarios (anfibologías, polisemias, paradojas, antonomasias, paronomasias, sentencias, ironías, repeticiones, anáforas, aliteraciones, quiasmos, paralelismos, neologismos, grecismos, figuras etimológicas, juegos de palabras, etc.), pero, en todo caso, la altísima frecuencia de uso del procedimiento antonímico -empleado unas veces como recurso exclusivo, otras como elemento principal, otras como secundario - lo convierten en un procedimiento estilístico de capital importancia en la obra de Marcial. Concretamente, el epigramista latino recurre a la antonimia (léxica o gramatical) en la punta epigramática del 36,9\% de sus composiciones, es decir, en algo más de un tercio ( $; !)$ de sus doce libros de Epigramas, ya sea mediante un esquema de «antonimia total», de «antonimia inicial y final» o de «antonimia final».

\section{BIBLIOGRAFÍA}

Barrio Vega, M. L. del 1989: «Epigramas dialogados: orígenes y estructura», Cuadernos de Filología Clásica 23, pp. 189-201.

Barwick, K. 1959: Martial und die zeitgenössische Rhetorik, Berlín.

Cañizares Ferriz, P. 1999: «El uso cómico de la antítesis en los epigramas de un solo dístico de Marcial», en Aldama, A. M. et alii (eds.), La filología latina hoy. Actualización y perspectivas, Madrid, vol. 1, pp. 83-93.

Ciocci, R. 1985: «Le 'durate' dell'epigramma in Marziale e nella tradizione. Lectura di Mart. III 58», Annali della Facoltà di Lettere e Filosofia 18, pp. 186-200.

Citroni, M. 1969: «La teoria lessinghiana dell'epigramma e le interpretazioni moderne di Marziale», Maia. Revista di letterature classiche 21, pp. 215-243.

Cruse, D. A. 1986: Lexical Semantics, Cambridge.

Duchácek, O. 1965: «Sur quelques problèmes de l'antonymie», Cahiers de Lexicologie 6.1, pp. 55-66.

Echave-Sustaeta, J. 1958: «Un procedimiento de estilo de Marcial», en Actas del I Congreso Español de Estudios Clásicos, Madrid, pp. 427-433.

Estefanía, D. 1991: Marcial. Epigramas completos, Madrid.

Fernández Valverde, J. 2004-2005: Marco Valerio Marcial. Epigramas; introd. de R. Moreno Soldevila, texto lat. por J. Fernández Valverde; trad. de E. Montero Cartelle, Madrid. 
Fortuny Previ, F. 1986: «En torno al vocabulario erótico de Marcial», Myrtia 1, pp. 73-91.

Galán Sánchez, P. J. 1996: «El tópico del sobrepujamiento en Marcial», en Aldama, A. M. (ed.), De Roma al siglo XX, Madrid, t. 1, pp. 255-262.

Galán Sánchez, P. J. 2000: «El uso de la antonimia en el libro I de los Epigramas de Marcial», Emerita. Revista de Lingüística y Filología clásica 68.2, pp. 307327.

García Hernández, B. 1987: «Estructuras léxicas en los Epigramas de Marcial», en Actas del Simposio sobre Marco Valerio Marcial, poeta de Bílbilis y de Roma, Zaragoza, pp. 237-258.

Guilbert, L. 1964 : «Les antonymes. Y a-t-il un système morpholexical des antonymes?», Cahiers de Lexicologie 4.1, pp. 29-36.

Holzberg, N. 2002: Martial und das antike Epigramm, Darmstadt.

Janka, M. 2006: «Paelignus, puto, dixerat poeta (Mart. 2.41.2): Martial's Intertextual Dialogue with Ovid's Erotodidactic Poems», en Gibson, R., Green, S. y Sharrock, A. (eds.), The Art of Love: Bimillennial Essays on Ovid's Ars Amatoria and Remedia Amoris, Oxford, pp. 279-297.

Kruuse, J. 1941: «L'originalité artistique de Martial, son style, sa composition, sa tecnique», Classica e Medievalia 4, pp. 248-300.

La Penna, A. 1992: «L'oggetto come moltiplicatore delle immagini. Uno studio su Priamel e catalogo in Marziale», Maia 44, pp. 7-44.

Laurens, P. 1989: L'Abeille dans l'ambre: Célébration de l'épigramme de l'époque alexandrine à la fin de la Renaissance, París.

Lessing, G. E. 1839: «Zerstreute Anmerkungen über das Epigramm, und einige der vornehmsten Epigrammatisten», en G. E. Lessings sämmtliche Schriften hrsg. von K. Lachmann, Berlín, pp. 425-528.

Malnati, T. P. 1984: The Nature of Martial's Humour, Johannesburgo.

Montero, E. 1991: «Recursos léxicos en el epigrama erótico de Marcial», en Ramos, A. (ed.), Mnemosynum C. Codoñer a discipulis oblatum, Salamanca, pp. 189-197.

Montero, E. 2004-2005: Marco Valerio Marcial. Epigramas; introducción de R. Moreno Soldevila, texto latino preparado por J. Fernández Valverde, traducción de E. Montero Cartelle, Madrid.

Muñoz Jiménez, M. J. 1996: «Rasgos comunes y estructura particular de Xenia y Apophoreta de Marcial», Cuadernos de Filología Clásica. Estudios Latinos 10, pp. $135-146$.

Pizarro Sánchez, J. 1999: «La anfibología en Marcial y el Corpus Priapeorum», en Aldama, A. M. et alii (eds.), La filología latina hoy. Actualización y perspectivas, Madrid, vol. 1, pp. 225-235. 
Ramírez de Verger, A. 2001: Marcial. Epigramas (Introducción general de J. Fernández Valverde), Madrid.

Rodriquez, M. T. 1981: «Il linguaggio erotico di Marziale», Vichiana 10, pp. 91117.

Salemme, C. 1976: Marziale e la «poetica» degli oggetti. Struttura dell'epigramma di Marziale, Nápoles.

Salemme, C. 1987: «Alle origini della poesia di Marziale», Orpheus. Revista di umanità classica e cristiana 8 , pp. 14-49.

Sánchez Salor, E. y Chaparro, C. 1984: Francisco Sánchez de las Brozas, Obras. Escritos retóricos. Introducción, traducción y notas, Cáceres.

Sullivan, J. P. 1989: «Martial's 'Witty Conceits': Some Technical Observations», Illinois Classical Studies 14, pp. 185-199.

Sullivan, J. P. 1991: Martial: The Unexpected Classic. A Literary and Historical Study, Cambridge.

Szelest, H. 1981: «Humor bei Martial», Eos 69, pp. 293-301.

Varo, C. 2007: La antonimia léxica, Madrid.

Watson, P. A. 2005: «Non tristis torus et tamen pudicus: The Sexuality of the Matrona in Martial», Mnemosyne 63.1, pp. 62-87.

Fecha de recepción de la primera versión del artículo: 08/06/2010

Fecha de aceptación: 07/12/2010

Fecha de recepción de la versión definitiva: 11/01/2011 